\title{
Presença de coliformes, bolores e leveduras em amostras de mel orgânico de abelhas africanizadas das ilhas do alto rio Paraná
}

\author{
Presence of coliforms, molds and yeasts in organic honey samples of Africanized honeybees from \\ Paraná River islands
}

\author{
Eloi Machado Alves ${ }^{\mathrm{I}}$ Vagner de Alencar Arnaut de Toledo ${ }^{\mathrm{II}}$ Luis Carlos Marchini ${ }^{\mathrm{II}}$ \\ Maria Josiane Sereia ${ }^{\mathrm{I}}$ Augusta Carolina de Camargo Carmello Moreti ${ }^{\mathrm{IV}}$ Emi Rainildes Lorenzetti $^{\mathrm{V}}$ \\ Carolina Antunes Neves ${ }^{\mathrm{I}}$ Alethéia Alves Santos ${ }^{\mathrm{VI}}$
}

\begin{abstract}
O presente trabalho foi desenvolvido para caracterizar a microbiota do mel produzido nas ilhas Floresta e Laranjeira do alto rio Paraná, na região de Porto Brasílio, Paraná (PR). O mel foi coletado diretamente das melgueiras das colônias avaliadas, em três apiários distribuídos nas ilhas Floresta e Laranjeira. O período de coleta das amostras de mel foi de novembro de 2005 a fevereiro de 2006, perfazendo o total de 24 amostras de mel orgânico produzido por abelhas Apis mellifera africanizadas. Seguindo o método das normas internacionais da Compendium of Methods for the Microbiology Examination of Foods, os parâmetros analisados foram: presença de coliformes a $35^{\circ} \mathrm{C}$ e $45^{\circ} \mathrm{C}$ e quantificação de bolores $e$ leveduras. Verificou-se que todas as amostras apresentaramse em conformidade com o Regulamento Técnico MERCOSUL de Identidade e Qualidade do Mel (MERCOSUL/GMC/RES no 15/94). As amostras analisadas indicaram excelente qualidade microbiológica para o mel orgânico.
\end{abstract}

- NOTA-
Palavras-chave: análise microbiológica, Apis mellifera, qualidade do mel.

\section{ABSTRACT}

This research was carried out to characterize the microbial flora of the organic honey produced in Paraná River islands. The honey was directly collected in the evaluated colonies, in three apiaries distributed at Floresta and Laranjeira Islands. The collection period was from November 2005 to February 2006. It was evaluated 24 organic honey samples produced by Africanized honeybees. Following the international standard Compendium method for the Microbiology Examination of Foods, the analyzed parameters used were: presence of coliforms at $35^{\circ} \mathrm{C}$ and $45^{\circ} \mathrm{C}$, and molds and yeasts quantification. All samples were in conformity with the MERCOSUL Technical Regulation Identity and Quality for Honey (MERCOSUL/GMC/RES no. 15/94. The analyzed samples indicated excellent microbiologic honey quality.

Key words: microbiologic analysis, Apis mellifera, quality of the honey

O mel é um produto natural originado do néctar das flores e de outras partes extraflorais, sendo amplamente consumido devido ao seu sabor agradável e por representar uma importante fonte de energia. Sua microbiota é constituída por microrganismos presentes no estado esporulado, como as bactérias do gênero Bacillus, e outros ocasionais ou acidentais, como fungos dos gêneros Penicillium, Mucor e Saccharomyces, os quais são incorporados ao mel pelas

'Programa de Pós-graduação em Zootecnia, Universidade Estadual de Maringá (UEM), Maringá, PR, Brasil.

IIDepartamento de Zootecnia, UEM. Av. Colombo, 5790, bloco J45, 87020-900, Maringá, PR, Brasil. E-mail: abelha.vagner@gmail.com. Autor para correspondência.

IIIDepartamento de Entomologia, Fitopatologia e Zoologia Agrícola, Escola Superior de Agricultura Luiz de Queiroz (ESALQ), Universidade de São Paulo (USP), Piracicaba, SP, Brasil.

${ }^{\mathrm{IV}}$ Instituto de Zootecnia, Nova Odessa, SP, Brasil.

vDepartamento de Agronomia, UEM, Maringá, PR, Brasil.

${ }^{\mathrm{VI}}$ Departamento de Biologia, UEM, Maringá, PR, Brasil. 
próprias abelhas da colônia, durante as operações de coleta, preparo do néctar e pólen, ou de maneira fortuita por manipulações pouco higiênicas, durante as etapas de coleta e processamento do mel (SNOWDON, 1999).

O mel com certificação de orgânico é definido como desprovido de qualquer contaminação química, incluindo aquela associada ao processo migratório das abelhas em busca de boas floradas, que não são controladas diretamente pelos apicultores e podem estar contaminadas com produtos químicos até o processo de embalagem final, e a exigência básica é a possibilidade de controlar a procedência do produto e o processo produtivo (BUAININ \& BATALHA, 2007).

O objetivo deste trabalho foi caracterizar a microbiota de amostras de mel orgânico de Apis mellifera africanizada, coletadas nas ilhas Floresta e Laranjeira do alto rio Paraná, para verificar se estão em conformidade com a legislação vigente.

Foram coletadas amostras de mel orgânico produzido em três apiários, localizados no alto rio Paraná, nas imediações de Porto Brasílio, em Querência do Norte, Paraná (PR). Dois desses apiários encontramse instalados na Ilha Floresta (Apiário A - S 2251’27,3"; W 53²9’35,6" e Apiário B - S 2254’24,2"; W 533’ 51,9") e um apiário, na Ilha Laranjeira (Apiário C - S 2253'59,0"; W 5333’51,9”').

Foram analisadas 24 amostras de mel orgânico, sendo 22 amostras coletadas diretamente nas melgueiras das colônias, sempre que possível de acordo com o armazenamento mensal de mel nas colméias marcadas. Os favos coletados foram embalados em sacos plásticos novos para evitar contaminação secundária, observando as boas práticas apícolas. As outras duas amostras foram obtidas junto aos apicultores, após a coleta realizada por eles em seus respectivos apiários. O período de coleta efetiva de mel ocorreu entre novembro de 2005 e fevereiro de 2006.

As análises foram realizadas no Laboratório de Insetos Úteis do Departamento de Entomologia, Fitopatologia e Zoologia Agrícola da Escola Superior de Agricultura, “Luiz de Queiroz”, Campus de Piracicaba da Universidade de São Paulo. As amostras foram analisadas para a presença de coliformes a $35^{\circ} \mathrm{C}$ e $45^{\circ} \mathrm{C}$ $\left(\mathrm{NMP} \mathrm{g}^{-1}\right.$ ) e enumeração de bolores e leveduras (UFC $\left.\mathrm{g}^{-1}\right)$, seguindo a metodologia das normas internacionais da APHA (1992). A partir de 25g de mel, realizou-se a primeira diluição em $225 \mathrm{~mL}$ de água peptonada tamponada a $0,1 \%$. As preparações das diluições decimais subsequentes foram realizadas em tubos contendo $9 \mathrm{~mL}$ do mesmo diluente até $1 / 1000$. Cada diluição foi semeada em três tubos, contendo caldo Lauril Sulfato Triptose (LST), para a quantificação do número mais provável de coliformes (NMP). Para a quantificação de bolores e leveduras, semeou-se em profundidade $1 \mathrm{~mL}$ de cada diluição decimal seriada, em duplicata, utilizando o ágar batata dextrose (BDA) acidificado com ácido tartárico $10 \%$ até $\mathrm{pH} 3,5$. A incubação deu-se em estufa bacteriológica a $35-37^{\circ} \mathrm{C}$, por 48 horas, e $25^{\circ} \mathrm{C}$, por cinco dias, para os testes de NMP e contagem de bolores e leveduras, respectivamente. As amostras foram analisadas em triplicatas.

Conforme a tabela 1, em todas as amostras analisadas a contagem de coliformes a $35^{\circ} \mathrm{C} \mathrm{e} 45^{\circ} \mathrm{C}$ foi menor que 3,0NMP $\mathrm{g}^{-1}$, o que evidenciou segurança quanto à presença de coliformes e de patógenos entéricos. Esses resultados podem ser explicados pela composição físico-química do mel, que determina qual microrganismo será capaz ou não de se desenvolver (SILVA, 2000; SEREIA, 2005).

Alguns trabalhos referentes à microbiologia do mel demonstraram valores semelhantes aos valores do presente trabalho $\left(<3,0 \mathrm{UFC} \mathrm{g}^{-1}\right)$. Alguns desses estudos são: SEREIA (2005), que comparou as características microbiológicas de 17 méis orgânicos (11) e não orgânicos (6) produzidos na tríplice fronteira (entre os Estados de São Paulo, Paraná e Mato Grosso do Sul); SODRÉ et al. (2007), os quais analisaram 58 amostras de mel do Ceará (20) e Piauí (38).

Com o conhecimento das características do alimento, é possível predizer a microbiota que poderá se multiplicar nele, pois seu desenvolvimento é condicionado por diversos fatores extrínsecos, como temperatura e umidade relativa e por fatores intrínsecos, sendo os principais a atividade de água, o $\mathrm{pH}$, o potencial redox e a composição do alimento, além das condições físicas e sanitárias deste (BANWART, 1995; MUNDO et al., 2004). Portanto, essa ausência dos microorganismos estudados pode ter sido favorecida pela faixa de $\mathrm{pH}$ encontrada nas amostras analisadas, média de 3,58, variando entre 3,33 e 4,04, ocorrendo inibição da multiplicação dos microrganismos. Além disso, o teor de umidade encontrado foi de, em média, $18,85 \%$, variando de 17,37 a $21,70 \%$, suficiente para inibir o desenvolvimento de mofos e leveduras em condições ambientais e dos microrganismos nas amostras (Tabela 1).

Pode-se observar que as contagens de bolores e leveduras que encontramos foram menores do que aquelas verificadas por: SEREIA (2005), que

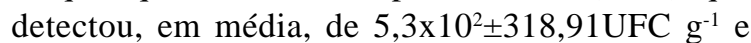
1,0x10² $\pm 92,87 \mathrm{UFC} \mathrm{g}^{-1}$, e SODRÉ et al. (2007), os quais encontraram valores entre $1,0 \times 10^{1} \mathrm{UFC} \mathrm{g}^{-1} \mathrm{e} 1,7 \times 10^{4} \mathrm{UFC}$ $\mathrm{g}^{-1}$ (Ceará), 1,0x10 ${ }^{1} \mathrm{UFC} \mathrm{g}^{-1}$ a 3,0x10² UFC g-1 (Piauí). 
Tabela 1 - Médias, desvio padrão, valores mínimos e máximos de coliformes a $35^{\circ} \mathrm{C}$, coliformes a $45^{\circ} \mathrm{C}$, bolores e leveduras das 24 amostras de mel orgânico de Apis mellifera africanizadas, coletadas nas ilhas do alto rio Paraná, no período novembro de 2005 a fevereiro de 2006.

\begin{tabular}{|c|c|c|c|}
\hline Análise realizada & Mínimo & Máximo & Padrão \\
\hline Coliformes a $35^{\circ} \mathrm{C}\left(\mathrm{NMP} \mathrm{g}^{-1}\right)$ & $<3$ & $<3$ & - \\
\hline Coliformes a $45^{\circ} \mathrm{C}\left(\mathrm{NMP} \mathrm{g}^{-1}\right)$ & $<3$ & $<3$ & - \\
\hline Contagem de bolores e leveduras (UFC g ${ }^{-1}$ ) & $<10^{1}$ & $3,8 \times 10^{1}$ & $1,0 \times 10^{2}$ \\
\hline Média (UFC g g $\left.{ }^{-1}\right)$ & $1,1 \times 10^{1}$ & & \\
\hline
\end{tabular}

NMP=Número Mais Provável; UFC = Unidade Formadora de Colônia.

Os métodos de análise aplicados neste estudo constituíram uma ferramenta eficiente e rápida para o diagnóstico de comprovação da qualidade microbiológica das amostras de mel. Os resultados observados apresentaram-se dentro dos parâmetros estabelecidos e aceitos pelos órgãos oficiais e pela comunidade científica, permitindo atestar excelente qualidade para o mel orgânico produzido por abelhas africanizadas nas ilhas Floresta e Laranjeira, nas imediações de Porto Brasílio (PR).

\section{AGRADECIMENTO}

Ao Conselho Nacional de Desenvolvimento Científico e Tecnológico (CNPq), pelo apoio financeiro (processo número 151242/2004-6).

\section{REFERÊNCIAS}

APHA (AMERICAN PUBLIC HEALTH ASSOCIATION). Standard methods for the examination of water and wastewater. Washington, 1992. p.4-93.

BANWART, G.J. Basic food microbiology. 2.ed. Westport, CT: AVI, 1995. 784p.
BUAININ, A.M.; BATALHA, M.O. Cadeias produtivas de flores e mel. In: _. Mel. Brasília: MAPA, 2007. p.85-139.

MERCOSUL/GMC/RES no 15/94. Regulamento Técnico MERCOSUL de Identidade e Qualidade do Mel. Disponível em: http://www.inmetro.gov.br/barreirastecnicas/ PDF/GMC_RES_1994-015.pdf. On line. Acesso em: $04 \mathrm{fev}$ 2009.

MUNDO, M.A. et al. Growth inhibition of foodborne pathogens and food spoilage organisms by select raw honeys. International Journal of Food Microbiology, Geneva, v.97, n.1, p.1-8, 2004.

SEREIA, M.J. Caracterização físico-química, microbiológica e polínica de amostras de méis orgânicos e não orgânicos produzidos por Apis mellifera L. (Hymenoptera: Apidae). 2005. 115f. Dissertação (Mestrado em Zootecnia - Produção Animal) Programa de Pós-graduação em Zootecnia, Universidade Estadual de Maringá.

SILVA, J.A. Tópicos da tecnologia dos alimentos. São Paulo: Varela, 2000. 227p.

SNOWDON, J.A. The microbiology of honey - meeting your buyers specifications (Why they do what they do). American Bee Journal, Hamilton, v.139, n.1, p.51-59, 1999.

SODRÉ, G.S. et al. Conteúdo microbiológico de méis de Apis mellifera (Hymenoptera: Apidae) dos Estados do Ceará e Piaú. Boletim de Indústria Animal, Nova Odessa, v.64, n.1, p.3942, 2007. 